\title{
Women's Vulnerabilty to a Seasonal Hazard: Their Capacity to Adapt and Their Resilience
}

\author{
Alison Cottrell \\ James Cook University, Australia
}

\begin{abstract}
W Jomen as a group may be more vulnerable to the impact of hazards, but at an individual level, they also have capacity to adapt to changing circumstances in ways that contribute to their own resilience. This paper provides examples of the ways in which some women adapt to a recurrent natural hazard to which they are exposed, in turn, providing insights on adaptive capacity at a personal level.
\end{abstract}

Keywords: hazards, women vulnerability, resilience, adaptive capacity

Women's disaster experiences are a mosaic of need and capability as richly textured, intricate, and colourful as women's many cultures. The ongoing process of documenting how and with what effect gender relations place women at risk, must be supplemented by images of women as active community responders. (Enarson \& Morrow, 1998, p. 8).

Enarson and Morrow (1998) argue that on balance, it is women who are most at risk from hazardous situations, particularly as they then evolve into disastrous events (see also Blaikie, Cannon, Davis, \& Wisner, 1994; Hewitt, 1995; Hewitt, 1997). Morrow and Phillips (1999) and Fordham (1999) suggest that women's experiences of hazards are in some ways unique and embedded with varying levels of vulnerability but also with differences in capacities to respond and be resilient. The research reported here was originally conducted for the purposes of identifying strategies for dealing with the northern Australian 'wet season' that might be useful for other women, and resulted in the production of material that could be used in posters and pamphlets and is available online for the use of local governments in Queensland. Another outcome of the research is a picture of the diversity of women's experiences in what might be described as a 'routine' hazard, flooding and cyclones in northern Australia. In particular, what became apparent was the interaction between what can be described as social structural characteristics of the women concerned and their human agency to adapt to changing circumstances, but in ways that suit their situation.
In the context of this research, to be resilient may rather loosely considered to be the capacity to 'bounce back' from a situation, but it is essential to recognise that this is not meant to imply returning to a previous state. People's lives are rarely the same after experiencing a major shock such as a disaster. Also, while resilience and vulnerability coincide in the context of hazards, they are not necessarily opposite ends of a single spectrum (Buckle \& Marsh, 2000; Handmer 2003; King, 2001) and while 'we are all vulnerable', it is the capacity to cope that contributes to our resilience (Handmer, 2003).

\section{Conducting the Research}

A grounded theory approach was taken to the research, using mixed methods (Berg, 2001; Ezzy, 2002; Rice \& Ezzy, 1999; Strauss \& Corbin, 1994). Originally, it was proposed to use only focus group discussions as the means of obtaining data. This proved somewhat problematic, lack of interest being the main issue. In itself, this would seem to confirm views that people tend to view the wet season hazards as not particularly important, or 'routine'. The final data collection methods included focus group discussions, telephone surveys and individual interviews. Sampling was opportunistic, depending on responses to advertisements and referrals from other people or randomised telephone numbers depending on the community concerned. The discussions focused on exploring whether women perceived the wet season to be a problem, how they prepared for it, what

Address for correspondence: Alison Cottrell, School of Earth and Environmental Science, James Cook University, Townsville, Qld 4811, Australia. E-mail: alison.cottrell@jcu.edu.au 
issues arose for caring for dependents and what advice they would recommend for newcomers to their region. It was decided to specifically approach women with dependents because we assumed that their responsibilities would make them more aware of the types of strategies that were necessary to deal with the natural hazard. As well, we recognised that women remain those mainly responsible for caring for the young and the aged in Australia (Poole \& Issacs, 1997; Poole, 2005). Most women were interviewed about perspectives on their own experiences, but there were several interviews with women who have responsibilities for others in formal settings outside the family who provided a broader perspective.

Forthergill (1998) suggests more qualitative indepth research is necessary to gain a better understanding of women's lived experiences in the disaster context, and argues that it is very important that we hear women's stories from their own point of view, if we are to fully understand their experiences. Although socioeconomic indicators are widely used, their limitations for assessing vulnerability and resilience to hazards is addressed by King (2001), and Marsh and Buckle (2000). King (2001) identifies issues of 'scale, data decay, relevance and weighting of indicators, and the way in which our definitions of community and vulnerability affect our selection of indicators from such data bases. These indicators also tend to obscure the diversity of experiences within a given demographic (Enarson, 1998). For example, the experiences of women in general, or those of a particular socio-economic or ethnic group can be over-generalised if the discussion focuses at the level of structural indicators. The research that is reported here provides good examples of how it is that we get such diversity in different demographic groups. The implications of this will be discussed later in the chapter.

\section{Women's Resilience}

The contents of the textbox on the previous page are snapshots of women's lives in northern Australia as they prepare to meet the seasonal needs of a wet season. They each have responsibilities that make their lives busy.

It's early November in Townsville. It is Saturday morning and the temperature is $37.5^{\circ} \mathrm{C}-$ an early burst of heat that serves as a timely reminder of what is to come over the next few months. A woman has a baby on her hip, a 3- yearold investigating the percussion properties of saucepans, and a 6 -year-old outside bouncing on the trampoline. Time to get the air-conditioners organised or there will be no nap for the baby this afternoon and grumpy kids tomorrow if they don't sleep tonight. Clean the filters and get out as much dust as possible - another task to add to the day. It is the first task for getting ready for the wet season. Because they camp regularly, she only needs to check up on the camping box to make sure emergency supplies are in place.

Further north at the Bloomfield River, another woman notices the signs of coming rain. At first it won't be heavy, but it will be enough for the creeks to cut the road into Cairns making shopping and health visits more precarious. Feeding the people in her community, who are old and/or disabled, through the community care program becomes just that more difficult and requires just that bit more planning and juggling. The big kitchen she organises requires supplying on a regular basis. Two weeks supply is as much as they can store most of the time. This is more than most people in the community can manage because of the way their income is organised and their social obligations for sharing with other relatives. Somehow she always manages to meet the needs.

Across the cape in the Gulf of Carpentaria, at Normanton, the monsoonal trough has come south and a woman is planning a trip to Cairns to stock up for the wet season. She will need enough of the essentials to last 4 months. This means canned and dried food, long-life milk, batteries and medical supplies. Before she goes to Cairns she needs to have the air-conditioners serviced and make sure there is enough fuel to run the generator for a week. So there is a reduced risk of being stuck on the way, she logs in to the Bureau of Meteorology website to check on river heights and potential rain. Her eldest child is at boarding school in Cairns. When she gets to Cairns she needs to visit the people her child can stay with if a cyclone comes and can't get home when school finishes. It all comes together in the end.

At the other side of the country in Broome, a woman has just had her second successful art exhibition. Her novel presentation of themes that build on her Indigenous heritage has been well received by locals and visitors alike. She is a single parent living in rental accommodation with her four children. The heat is starting to build intensively now and there is a need to carefully store what has not been sold. This is hard because the house is not fitted with shutters on the windows and should there be a cyclone not only her livelihood will be threatened but it could be a dangerous situation for the children. This means she may have to evacuate with the children to the greater security of her mother's house. Despite her recent success, money is still tight and her capacity to stock up on things is limited, so she concentrates on the absolute essentials with a view to buying extras should a cyclone warning be declared.

Figure 1

Different women, different ways. 
Should a cyclone occur or simply heavy rain that leads to isolation, they are potentially vulnerable. However, they are also resilient. To a large extent, that resilience is built into the way they organise their lives and prepare for the routine hazards that impacts on their lives. For some, resilience is to do with financial capacity, for others it is the capacity to tap into the resources and support provided by family and friends, or the capacity to plan well, or to access government information and services that may be available.

To examine the variety of ways that women, unconsciously, negotiate the relationships between structure and agency in the context of a routine hazard, this discussion will focus on the issues from three perspectives:

- Indigenous women

- the interactions between location and socioeconomic status

- one particular woman's perspective on the hazard.

\section{Indigenous Women}

Indigenous women in Australia are part of a structurally disadvantaged group (Altman, 2004; Altman \& Hunter, 2003a; Altman \& Hunter, 2003b; Australian Bureau of Statistics, 2004). However, to describe their experiences as a uniform one in the context of hazards would not be wise. From this research a range of different kinds of experiences can be identified.

An example of how Indigenous women's resilience can be undermined, particularly in a hazard situation, is evident from the evacuation of a community in Western Australia. In this situation, where the mainstream community feels that they can evacuate a community from their homelands because of an outsider's perception of their vulnerability, is perhaps the quintessential example of structural disadvantage.

What happened was that as a cyclone was approaching the region, the community was evacuated to a nearby urban centre. The people were housed in tents on a sportsfield in the town. They were there for several weeks, unable to return to their country (homelands) because of flooding. During that time relations between the host community and the evacuees became quite tense. The host community, which had also experienced some impact from the cyclone, tended to blame on the evacuees anything that went wrong in the town. The evacuees were finding it very difficult to rebuild their lives, because they were so far from their homes. Their capacity to bounce back, that is be resilient, was compromised. The women in particular were in a situation from which it was very difficult to recover, because they could not focus on their normal activities. In addition the isolation from their homes exacerbated their feelings of disquiet. They became isolated from the capacity to gather traditional foods, which would have been helpful in the situation.
Emergency services personnel were of the view that in future it would be preferable for there to be buildings in the community that people could use so the women could return to their homes as quickly as possible afterwards. This is the case in some other indigenous communities where people will go to other family members who are viewed to be living in safer housing (McLachlan, 2003; Skertchly \& Skertchly, 2000). As well, most communities have a store, which even if it is closed because of weather conditions, is something of a backup. Should the store supplies not be available traditional foods fished, gathered or hunted are available. There is a clear recognition then that the normal capacity to recover or to be resilient for this group of women was denied them by their removal from their country.

Another example of the differences in women's experiences is for the group of Indigenous women who live in town camps (see Monaghan 2004 for a discussion of types of Indigenous settlements). That is, they have poor living standards on the edge of town. For these women there are a number of really complicated issues. Many are on welfare payments. If their husbands gain salaries, they are usually from various community employment schemes. The women tend to be more occupied with caring for children than being in paid employment. For women who are reliant on incomes from their husbands, there are complications from the ways that salaries are paid. The wet season (heavy rain season) coincides with the Christmas holiday. Consequently, there is a huge payout in November and then no more money again until the end of January. What usually happens in this situation is that money often gets spent by the men on nonroutine activities such as partying and gambling, leaving the women short of resources to meet family needs. The women in this situation are buying breakfast and lunch for the children on the way to school, and are buying evening food in the afternoon after collecting the children from school. They have little access to cooking and storing facilities. In particular, refrigeration is out of the question because there is no electricity supply. ${ }^{1}$

In this situation, domestic violence is not uncommon. The managers of women's refuges find themselves in a very difficult situation because refuges need to close under the conditions of a cyclone and women have to go back to their homes where they are more vulnerable to domestic violence. However, one refuge manager indicated that especially Indigenous women who had used refuge services, sought other types of social service information from the refuge, including what to do in the event of a cyclone. This might be interpreted by some as dependency, but it might also be seen as women effectively using whatever resources become available.

Indigenous women living more mainstream lifestyles in regional towns talked about using family networks to carry them through cyclones or flooding. Women reported feeling happier to be with a bigger family group 
in those circumstances, especially if they were moving to a more substantial building. They also relied on male relatives to help secure buildings and get rid of rubbish. This is similar for members of mainstream communities who were interviewed. There are also Indigenous women who have occupations which place them in situations of responsibility for others. As indicated in Figure 1, at a remote Indigenous community a woman catering for the needs of Indigenous and mainstream vulnerable aged in her area has to plan for meeting their needs during hazardous weather. This woman contributes to the community's resilience through her quite capable organisational capacity. Indigenous women who are more integrated into mainstream employment have greater economic resources available to them to see through the situation of hazardous weather. It is quite clear then, that using the demographic 'Indigenous woman' could lead to a 'glossing over' of the diversity of experiences of those women.

\section{Socioeconomic Status and Location}

For women in mainstream communities there is also considerable variation in resilience to hazardous weather. Women in large urban centres are used to utilities, services and business being operable after about 3 days of a major weather event. Indeed, in the past, emergency service advertising advises people to be prepared for approximately 3 days without power and other services. In smaller regional centres women tend to need to be organised to meet household needs for longer periods. Women living in remote townships need to be prepared for much longer periods without access to outside assistance and resources. Again, there is considerable variation in capacity to be resilient in each of the types of locations. In remote locations, the capacity to 'sit out' long periods is made much easier if there is financial capacity to buy in bulk and store. This also requires substantive housing and storage capacity, which implies access to substantive disposable income. However, as with the case of Indigenous women, women on low incomes do manage, especially if they are experienced with the area and plan well. An example of this is for a woman living in a situation where, once the wet season begins, the community can be isolated for long periods of time. In this case she stocks up on long-life items on a gradual basis, adding extras to her shopping list in the lead-up to the wet season.

If there is someone ill or with a disability in the household, matters become more complicated and resilience becomes compromised. It also depends on what other events have happened to the household, and peoples' expectations. For example, in a regional centre in the aftermath of a cyclone, there were some women from some households who could not cope with the idea of being without air-conditioning and running water so they booked into a local motel until utilities were functional. However this might be viewed, it is an example of resilience that is dependent on disposable income. However, in another more remote town, a woman who was profoundly deaf had great difficulty coping, and her resilience was compromised. In this case, she focused on the inability to easily obtain batteries for her hearing aids. As the conversation proceeded, it became clear that she was also missing her friendship networks and the urban lifestyle of the place where she lived until recently. In this new location she was clearly feeling vulnerable because her support networks were missing.

Support networks remain important for many women, irrespective of their income. For many women their networks are local, but for women who have children away at boarding school, they need networks in the city of the school so that if flooding prevents the children coming home they have a back-up place to say. This requires the women to be organised as well. This organisational capacity is also reflected in women who live in remoter areas, but use the Internet to source weather information. They will seek information about rainfall and river heights that are relevant to their situation. On the basis of this they will make decisions about whether or not to travel. If they need to travel to a major centre because they have an important medical or legal appointment, they may still travel, recognising the risk of being stuck in the city for a few days. In this case they will organise friends or relatives to care for children at their home. In all types of locations women of varying financial capacity have resilience, but it may be evidenced in different ways.

\section{One Woman's Way}

A nursing sister, Karen, ${ }^{2}$ is an example of what human agency means in an individual case. Karen is a senior theatre nurse at a major hospital. During times of high weather hazard, she is expected to be available for work. Karen, who is married and has three children, begins preparing for the wet season by starting to stock up around November, at the same time she starts to prepare for Christmas celebrations. Each week she adds extra items to her shopping list. She checks her stores of longlife food products, batteries, and torches. Like many of the other women we interviewed, Karen does not have an emergency kit, but says she knows where the essentials are and can gather them up in a short time. She also has photographs packaged for easy access should she need to evacuate.

When hazardous weather reports start she listens more intently to the radio. Because she has grown up in the region, her view is that she can't 'panic' on every weather report. She continues about her very busy life, keeping in touch with the latest weather reports, making judgements about whether 'this time it is the real thing'. Her husband checks weather reports on the Internet and keeps her informed about the latest reports. Karen tends to focus on things that need to be done inside the house, 
while her husband concentrates on the outside of the house. In her town are her aged mother and her sister who is also married and has children. Karen is the elder sister and tends to take responsibility for her aged mother. Because Karen may be called into work, she relies on her sister to take responsibility for her mother should a cyclone occur. This is an example of mixed responsibilities and also reliance on family networks.

Karen is very resilient, but that does not mean that she doesn't feel the vulnerability associated with hazardous weather. In previous cyclones she had to juggle the need to report for work, her concern about whether her sister would be available to check on their mother, and her concerns about not being able to help her husband at home. In particular, when the children were toddlers, she was concerned that they would have to be left inside on their own while her husband checked what was happening outside the house. This concern is not without basis. In the last cyclone a large tree fell, narrowly missing their car and house. Despite the fact that she is needed at work, she can return home should the need arise. However, because the roads flood, she may not be able to easily get from work to home.

Karen's planning, family networks and capacity to adapt as circumstances arise all contribute to her, and her family's, resilience. As well, in her professional capacity, she contributes more broadly to resilience in her community.

\section{Discussion}

This research contributes to an understanding of why we have so much trouble using demographic characteristics as indicators of vulnerability and resilience (this is not to suggest that they are totally without usefulness - see Handmer, 2003). The picture provided of the complexity of women's lives and their responses to hazards helps to give voice to a diversity that is so often denied women by assuming they are generally more vulnerable in hazardous situations. The diversity of ways that women contribute to personal, family and community resilience also belies the usefulness of prescriptive approaches to hazard mitigation, especially for women. This then, is about human agency (Giddens, 1984; Enarson \& Morrow, 1998). As Enarson and Morrow suggest:

The multiple intersection of influences of gender, class and race on human agency vis a vis environmental hazards are lost in the move to abstract disasters from actual human experience (1998:28) and ... agency is expressed in the form of coping strategies. (p. 38)

Social structural position clearly impacts on women's capacity for human agency, which in turn impacts on their capacity to prepare and to be resilient in the context of routine hazards. However, if we ignore women's agency, we disenfranchise them further by denying their contribution as role models for coping and resilience.
Human agency is implicit in contemporary emergency management practices which more explicitly rely on individuals and communities to be more self-sufficient in their responses to hazards. Agency is also clearly explicit in the actual responses of people to hazards. Many people clearly take action where they can. What is clear from this research is that women should not be viewed as 'invisible', nor considered as totally helpless victims, but as affected people with varying capacities that contribute to individual, family and social resilience (see also Scanlon, 1998).

Women's voices about the way they prepare for hazardous situations provide insights that are helpful to our understanding of the way people approach mitigative behaviours. Paton et al. (2000) and Paton and Johnston (2001) also discuss the nature and quality of adaptive, competencies and procedures similar to those exemplified by the women interviewed for this research. Although Paton et al. (2000) and Paton and Johnston (2001) take a much more quantitative approach to the issue, the more qualitative approach taken in this research also enriches our understanding of those issues where people are making decisions about how to act in the context of a hazard.

The implications of this research on women and resilience are not only applicable to the Australian context. Paton (2005) suggests:

\begin{abstract}
While research on readiness and resilience in Western populations has flourished over recent years, fundamental research into these processes in other cultures is sparse. Similarly, little research has been undertaken into identifying resilience in indigenous populations. We may be doing affected populations an injustice if assistance is provided in ways that fail to complement these intrinsic capacities. If the research and practitioner communities are to confront this issue, more attention needs to be directed to understanding the relationship between cultural, ethnic and religious characteristics and adaptation to natural hazard consequences in the context of hazard impacts (p. 2).
\end{abstract}

Similarly, a focus on developing capacity and resilience in the context of international aid is also recommended in the 2004 World Disasters Report (IFRCRCS, 2004). The suggestion is that despite formal recognition by aid agencies, there is a necessity to go beyond a focus on vulnerability. Based on the articles included in the report, which show evidence of resilience in the most surprising and creative ways, the view is that there is a need to:

... dispel the myth of the helpless victim and the infallible humanitarian, and to put disaster affected people and their abilities at the centre of our work. (IFRCRCS, 2004, p. 9)

These comments apply equally to emergency management organisations in both developing and developed countries. Denying people's agency, and women's in particular, also denies the capacity for response and long-term resilience of individuals, households and communities to hazards of all kinds. Researchers need to develop a clearer understanding of how structure and agency interact in the 
context of hazards. In addition, there is a need to contribute to the design of strategies that utilise individual, household and community capacity to more systematically foster the development of resilience to hazards (see also Enarson \& Fordham, 2001).

\section{Conclusion}

Despite media portrayal of communities, and women in particular, as helpless, ungrateful and dependent victims, and despite the real suffering they experience, women show evidence of considerable resilience in the face of natural hazards. This resilience is based on their capacity to prepare for hazards in ways that are relevant to their situation, needs, and their family's needs. Their capacity to link with extended families and friends and other community contacts is another important contributor to that resilience.

\section{Endnotes}

1 The type of electricity supply varies considerably across Indigenous communities. Supply varies from none at all to generators, to reticulated supply with meter boxes to allow payment in small ongoing amounts, to full reticulation and to reticulation supplemented with wind turbines.

2 A pseudonym.

\section{References}

Altman, J. (2004). Economic development and Indigenous Australia: Contestations over property, institutions and ideology? Canberra, Australia: Centre for Aboriginal Economic and Political Research, Australian National University. Available at http://www.anu.edu.au/caepr/Publications/ topical/Altman_Economic_Development_2004.pdf - 68k 30 jun 2004

Altman, J.C., \& Hunter, P.H. (2003a). Monitoring 'practical' reconciliation: Evidence from the reconciliation decade, 1991-2001 (Report No. 254/2003). Canberra, Australia: Centre for Aboriginal Economic and Political Research, Australian National University. Available at http://www.anu.edu.au/caepr/Publications/DP/2003_DP25 4.pdf - 73k - 25 nov 2003

Altman, J.C., \& Hunter, P.H. (2003b). Submission to the House of Representatives Standing Committee on Aboriginal and Torres Strait Islander Affairs Inquiry into capacity building in Indigenous communities. Canberra, Australia: Centre for Aboriginal Economic and Political Research, Australian National University. Retrieved October 23, 2003, from http://www.anu.edu.au/caepr/Publications/topical/CAEPR CapacityBuildingsub.pdf

Australian Bureau of Statistics. (2004). National Aboriginal and Torres Strait Islander Social Survey. Retrieved March 7, 2005, from http://www.abs.gov.au/Ausstats/abs@.nsf/0/ 9ad558b6d0aed752ca256c7600018788?OpenDocumentAus tralian.

Berg, B., (2001). Qualitative research methods for the social sciences. Boston: Allyn and Bacon.
Blaikie, P., Cannon, T., Davis, I., \& Wisner, B., (1994). At risk: Natural hazards, people's vulnerability, and disasters. London: Routledge.

Bureau of Meteorology. (2009). Available at http://www.bom. gov.au/

Cottrell, A., \& Anderson-Berry, L. (2003). Women's preparations for the wet season in Northern Australia (Report to Emergency Management Australia, Small Grants Program, Project 13/2002). ??Place of publication: ??Publisher.

Cottrell, A., Cunliffe, S., King, D., \& Anderson-Berry, L. (2001) Awareness and preparedness for natural hazards in remote communities: Bloomfield River Region and Rossville. Townsville, Australia: Centre for Disaster Studies James Cook University.

Enarson, E., \& Morrow, B.H. (1998). The gendered terrain of disaster. Miami, FL: Laboratory for Social and Behavioral Research, Florida International University.

Ezzy, D., (2002). Qualitative analysis: Practice and innovation. Sydney, Australia: Allen and Unwin.

Finlay, C.C. (1992). 'Floods, they're a damned nuisance': Women's experiences during flood time and meanings for 'disaster'. Unpublished honour's thesis, James Cook University, Australia.

Fothergill, A. (1999). An exploratory study of woman battering in the Grand Forks flood disaster: Implications for community responses and policies. International Journal of Mass Emergencies and Disasters, 17, 79-98.

Fordham, M. (1999). The intersection of gender and social class in disaster: Balancing resilience and vulnerability. International Journal of Mass Emergencies and Disasters, 17, $15-37$.

Glaser, B.A., \& Strauss, A. (1968). The discovery of grounded theory. Chicago: Aldine.

Giddens, A. (1984). The constitution of society: Outline of the theory of structuration. Berkeley, CA: University of California Press.

Handmer, J. (2003). We are all vulnerable. Australian Journal of Emergency Management, 18, 55-60.

Hewitt, K. (1995). Excluded perspectives in the social construction of disaster. International Journal of Mass Emergencies and Disasters, 13, 317-340.

Hewitt, K. (Ed.). (1997). Regions of risk: A geographical introduction to disasters. Harlow: Addison Wesley Longman.

IFRCRCS. (2004). World Development Report. Geneva: International Federation of Red Cross and Red Crescent Societies.

King, D. (2001). Uses and limitations of socioeconomic indicators of community vulnerability to natural hazards: Data and disasters in Northern Australia. Natural Hazards, 24, 147-156.

McLachlan, E. (2003). Seagulls on the airstrip: Indigenous perspectives on cyclone vulnerability, awareness and mitigation strategies for remote communities in the Gulf of Carpentaria. Australian Journal of Emergency Management, 18, 4-12.

Monaghan, J. (2004, April). Fire risk in Aboriginal peri-urban landscapes in North Australia. Report to the Bushfire Cooperative Research Centre, Melbourne, Australia. 
Morrow, B.H., \& Phillips, B., (1999). What's gender 'got to do with it'? International Journal of Mass Emergencies and Disasters, 17, 5-13.

Paton, D., Smith, L., \& Violanti, J., (2000). Disaster response: Risk, vulnerability and resilience. Disaster Prevention and Management: An International Journal, 9, 173-180.

Paton, D., \& Johnston, D. (2001). Disasters and communities: Vulnerability, resilience and preparedness. Disaster Prevention and Management: An International Journal, 10, 270-277.

Poole, M. (Ed.). (2005). Family: Changing families, changing times. Sydney, Australia: Allen \& Unwin.

Poole, M., \& Issacs, D. (1997). Caring: A gendered concept. Womens Studies International Forum. 20, 529-536.
Rice, P.L., \& Ezzy, D., (1999) Qualitative research methods. Melbourne, Australia: Oxford University Press.

Scanlon, J. (1998). The perspective of gender: a missing element in disaster response. In E. Enarson \& B.H. Morrow, The gendered terrain of disaster (pp. 45-52). Miami, FL: Laboratory for Social and Behavioral Research, Florida International University.

Skertchly, A., \& Skertchly, K. (2001) Human Aspects of the Katherine-Daly Flood Disaster. Australian Journal of Emergency Management, 15, 47-52.

Strauss, A., \& Corbin, J., (1994). Grounded theory methodology: An overview. In N.K. Denzin \& Y.S. Lincoln (Eds.), Handbook of qualitative research (pp. 273-285). Thousand Oaks: Sage. 